\title{
Çene yüz kırıklarının demografik özellikleri ve etiyolojik faktörleri: Retrospektif çalışma
}

\author{
Özkan Özgül(0000-0002-1735-3174) ${ }^{\alpha}$
}

Selcuk Dent J, 2018; 5: 67-72 (Doi: 10.15311/selcukdentj. 410678)

Basvuru Tarihi: 29 Mart 2018 Yayına Kabul Tarihi: 05 Nisan 2018

\section{Öz \\ Çene yüz kırıklarının demografik özellikleri ve etiyolojik faktörleri: Retrospektif çalışma}

Amaç: Bu çalışmanın amacı bölgemizde görülen çene yüz kırıklarının demografik ve klinik özelliklerini, etiyolojik faktörlerini ve tedavi protokollerini retrospektif olarak analiz etmektir.

Gereç ve Yöntemler: Çalışmamızda Nisan 2015- Kasım 2017 tarihleri arasında kliniğimizde çene yüz kırık tanısı ile tedavi edilmiş hastaların medikal kayıtları degerlendirmeye alındı. Yas, cinsiyet, etiyolojik neden, kırıgin lokalizasyonu, uygulanan tedavi yöntemi belirlenerek veri dağılımı analiz edildi.

Bulgular: Medikal kayıtların incelenmesi ile, 40'ı erkek (\%77), 12 'si kadın olan 52 hastada 62 çene yüz kırığı tespit edildi. Ortalama yaş 33.3 (9- 67), etiyolojik faktörler sırasıyla darp (\%42), trafik kazası (\%33), düşme (\%25) olarak bulundu. 62 kırığın \%92'si mandibulada; lokalizasyonlarına göre sırasıyla angulus (\%34), simfiz (\%31), kondil (\%14), korpus (\%8), ramus (\%5) ve \%8'i de maksillada görüldü.

Sonuç: Çene yüz kırıklarının etiyolojisi ve insidansı; sosyal, kültürel, ekonomik ve çevresel şartlara bağımlıdır. Farklı coğrafik, ekonomik ve sosyal özelliklere sahip olan ülkemizde yapılacak çok merkezli çalışmalara intiyaç bulunmaktadır.

\section{ANAHTAR KELIMELER}

Çene yüz kırıklar, etiyoloji, travma

Çene yüz bölgesinde görülen kırıklar hastanın yüz görünümünde degıssikliklere neden olarak tedavi edilmediği veya yanlış tedaviler uygulandığı takdirde fonksiyonel ve estetik açıdan önemli problemlere yol açabilmektedir. Çene yüz kırıklarının meydana gelmesinde öncelikle etkili olan faktörler: gelen kuvvetin şiddeti ve yönü, travma etkeninin kesit alanı, travmaya maruz kalan bölgenin anatomisi, kemiklerin kuvvete karşı gösterdiği direnç, kafanın duruş pozisyonu ve kas yapışıklıklarıdır. Çene yüz bölgesinde meydana gelen kırıkların \%45-75 ini mandibula kııkları oluşturmaktadır. ${ }^{1-3}$

Çene yüz kırıklarının etiyolojisi ve insidansı sosyal, kültürel, ekonomik ve çevresel faktörlere bağlı olup yaşanılan bölgeler arasında farklılıklar göstermektedir.

\section{ABSTRACT}

Demographic characteristics and etiological factors of maxillofacial fractures: Retrospective study

Background: The aim of this study is to retrospectively analyze the demographic and clinical features, etiological factors and treatment protocols of maxillofacial fractures in our region.

Methods: In our study, medical records of patients who were treated with a maxillofacial fracture in our clinic during the period of April 2015-November 2017 were evaluated.

Results: Examination of medical records revealed 62 maxillofacial fractures in 52 patients 40 male $(77 \%)$ and 12 female (\%23). Mean age was 33.3 (9-67), etiological factors were assault (42\%), trafic accident $(33 \%)$ and fall $(25 \%)$ respectively. Of these 62 fractures $92 \%$ was observed in mandible respectively as angulus (34\%), symphis (31\%), condyle $(14 \%)$, corpus $(8 \%)$, ramus $(5 \%)$ and $8 \%$ was observed in maxilla.

Conclusion: Etiology and incidence of maxillofacial fractures depends on factors such as social, cultural, economic and enviromental conditions. There is need for multi-centered study to be done in our country which has different geographical, economic and social characteristics.

\section{KEYWORDS}

Maxillofacial fractures, etiology trauma

Gelişmis, toplumlarda kırık etiyolojisinde darp ilk sırayı alırken, gelișmekte olan toplumlarda trafik kazaları ilk sıradadır. Bunlardan başka; düșme, is, kazaları, ateșli silah yaralanmaları ve spor kazaları da etiyolojik faktörler olarak sayılabilmektedir. ${ }^{4-5}$

Çene yüz bölgesi ve çevresi nöral ve vasküler açıdan zengin bir bölgedir. Bu bölgede uygulanacak tedavi protokolü doğru endikasyon, uygun ekipman, doğru anatomik bilgi, gerekli cerrahi bilgi ve tecrübeyi içermelidir. Bu bölgede bulunan anatomik yapılar tedavi başarısını direkt etki etmekte, bu yapılara zarar gelmesi halinde tedavinin başarısı olumsuz etkilenmektedir. ${ }^{2,6}$

Bu çalışmanın amacı kliniğimizde son 2 yıl içerisinde

\footnotetext{
${ }^{\alpha}$ Kırıkkale Üniversitesi Diş Hekimliği Fakültesi Ağız Diș ve Çene Cerrahisi Anabilim Dalı, Kırıkkale
} 
kırık teşhisi ile tedavi edilmiş hastaların yaş, cinsiyet, lokalizasyon, redüksiyon yöntemi ve etiyolojik faktörlerine göre sınıflandırarak analiz etmek ve retrospektif olarak güncel literatür ışığı altında değerlendirmektir.

\section{GEREÇ VE YÖNTEM}

Çalışmamızda 2015 Nisan - 2017 Kasım zaman dilimi içerisinde klinigimizde çene yüz kırığı tanısı ile tedavi edilmiş hastaların medikal kayıtları degerlendirmeye alındı. Çalışma Helsinki Deklarasyonuna uyumlu şekilde yürütüldü. Hastaların yası, cinsiyeti, etiyolojik neden, kırığn lokalizasyonu, uygulanan tedavi yöntemi, komplikasyonlar gibi veriler toplanarak degerlendirmeye tabi tutuldu. Olusțgu kemiğe göre kırıklar mandibula, maksilla ve bunlar da kendi içerisinde lokalizasyonlarına göre korpus, simfizparasimfiz, ramus, kondil, angulus, olarak yeniden ayrıldılar. Etiyolojik nedenler trafik kazaları, darp, düşme olarak sınıflandırıldı. Tedaviler açık (mini plak, , kapalı veya her iki redüksiyon şeklinde sınıflandırılarak, kapalı redüksiyonun (sadece intermaksiller fiksasyon) tipi, açık redüksiyonunun (mini plak, rekonstrüksiyon plağı, mini vida, tel ile fiksasyon) yaklaşım şekli ve kullanılan fiksasyon malzemeleri belirtildi.

\section{BULGULAR}

2015 Nisan-2017 Kasım zaman dilimi içerisinde kliniğimizde tedavi edilen 52 hastadaki 62 Çene yüz kırığının medikal kayıtları incelendi. Hastaların yası, cinsiyeti, etiyolojik neden, kırıgın lokalizasyonu, uygulanan tedavi yöntemi, komplikasyonlar belirlendi (Tablo1). Hastaların 40'ı erkek (\%77), 12'si kadın (\%23) olarak tespit edildi. Hastaların yaş ortalaması 33.3 olup; en küçüğü 9, en büyüğü ise 67 yaşındaydı. Ortalama kadın yaşı 30,08 iken ortalama erkek yaşı 34.28 bulunmuştur. 3 hasta 16 yaşından küçük, 33 hasta 16-40 yaş arası, 16 hasta da 40 yaşından büyük olarak tespit edildi.

Etiyolojik nedenler araştırıldığında darp 22 hasta (\%42) ile ilk sırada bulundu. Sonra sırasıyla 17 hasta (\%33) trafik kazası, 13 hasta (\%25) düşme olarak tespit edildi (Şekil 1).

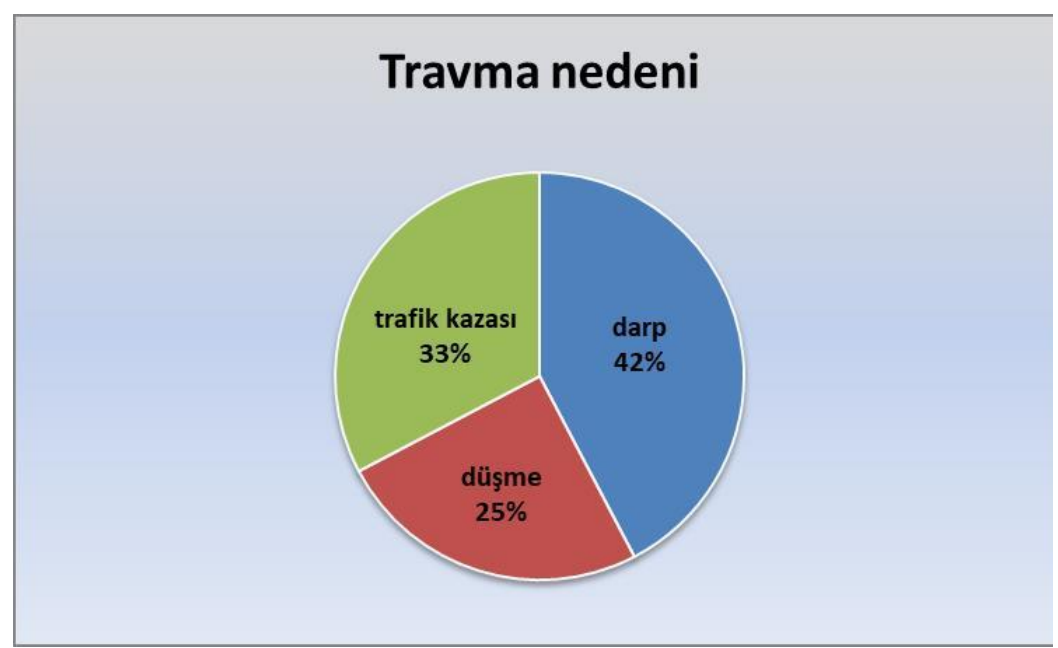

Şekil 1.

Travma etiyolojik nedenleri: darp 22 (\%42), trafik kazası 17 (\%33), düşme 13 (\%25)

Tedavisi gerçekleştirilmiş 62 kırığın 57'si (\%92) mandibulada, 5 (\%8) tanesi maksillada görüldü. Mandibula kırıklarında da lokalizasyona göre angulus kırıkları 21 (\%34) en sık karşılaşılan lokalizasyon olarak belirlendi. Diğer lokalizasyonlar sıklık sırasına gore simfiz 19 (\%31), kondil 9(\%14), korpus 5(\%8), ramus 3(\%5) şeklindeydi (Şekil 2).

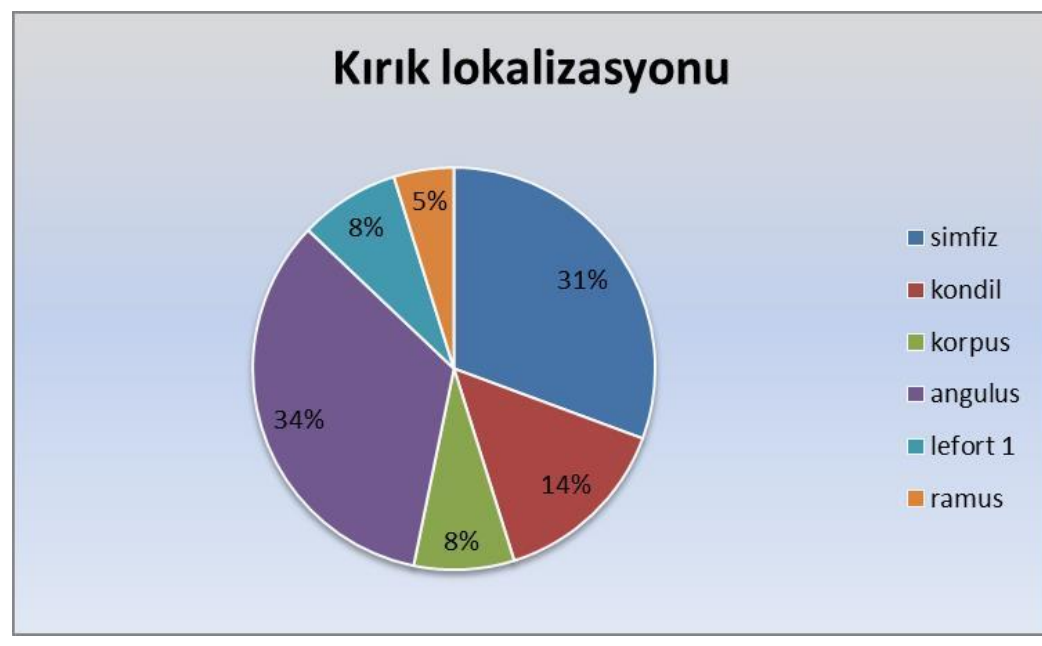

Şekil 2.

Çene yüz kırıklarının lokalizasyondaki dağılımı

Hastaların 7 tanesinin $(\% 13,5)$ kapalı redüksiyon ile yani sadece intermaksiller fiksasyon yöntemi ile tedavi edildiği saptandı. 45 hastanın da $(\% 86,5)$ açık redüksiyon ile yani plak ve vida ile kırıklarının tespitinin yapıldığı belirlendi. Açık redüksiyon ile tedavi edilmiş 8 hastaya da açık redüksiyondan sonra ortalama 2 hafta süreli intermaksiller fiksasyon yönteminin kullanıldığı belirlendi. İntermaksiller fiksasyon yöntemi olarak intermaksiller fiksasyon vidası (\%11), ark bar (\%10) ve tel (\%8) kullanıldığı belirlendi. (Şekil 3 - Şekil 4). 
Tablo 1.

Hastaların demografik özelliklerinin ve ve tedavi ayrıntılarının dağılımı

\begin{tabular}{|c|c|c|c|c|c|}
\hline Cinsiyet & Postop imf & Yaş & Neden & Plak/Vida/yaklaşım & Lokalizasyon \\
\hline e & ark bar & 27 & darp & - & simfiz \\
\hline e & - & 31 & darp & 2 plak/8 vida/ekstraoral & kondil \\
\hline e & - & 36 & darp & 2 plak/ 8 vida/intaroral & simfiz \\
\hline e & - & 63 & düşme & 1 plak/4 vida/intraoral & korpus \\
\hline $\mathrm{k}$ & tel & 33 & trafik $\mathrm{k}$. & 1 rekons plak/ekstaoral & angulus \\
\hline e & tel & 26 & trafik $\mathrm{k}$. & 2 plak/10 vida/intraoral & simfiz \\
\hline $\mathrm{k}$ & - & 18 & trafik $\mathrm{k}$. & 2 plak/10 vida/intraoral & Lefort 1 \\
\hline e & imf vida & 12 & trafik $\mathrm{k}$. & - & angulus/ramus \\
\hline $\mathrm{k}$ & - & 20 & düşme & 2 plak/10 vida/intraoral & angulus \\
\hline e & - & 39 & trafik $\mathrm{k}$. & 2 plak/ 8 vida/introral & simfiz \\
\hline e & - & 20 & darp & 2 plak/ 8 vida/introral & angulus \\
\hline e & - & 29 & darp & 1kompresyon plak/io & simfiz \\
\hline $\mathrm{k}$ & imf vida & 20 & trafik k. & 1rekons +2 plak/ekstraoral & ramus/angulus \\
\hline e & - & 19 & düşme & 3 plak/14 vida/intraoral & çift taraflı angulus \\
\hline e & - & 20 & darp & 1 plak/4 vida/intraoral & angulus \\
\hline e & - & 35 & düşme & 2 plak/ 8 vida/intraoral & simfiz \\
\hline e & imf vida & 41 & trafik $\mathrm{k}$. & 2 plak/10 vida/intraoral & Lefort 1 \\
\hline e & - & 18 & düşme & 1 plak/4 vida/intraoral & simfiz \\
\hline e & imf vida & 28 & düşme & - & kondil \\
\hline e & ark bar & 38 & darp & 2 plak/ 8 vida/intraoral & simfiz \\
\hline e & - & 47 & darp & 2plak/ 8 vida/ekstraoral & kondil \\
\hline $\mathrm{k}$ & - & 9 & trafik $\mathrm{k}$. & 5 plak/ 25 vida/io-eo & Lefort $1 /$ simfiz/ramus \\
\hline k & - & 26 & düşme & 2 plak/ 8 vida/intraoral & korpus \\
\hline e & tel & 18 & darp & - & kondil \\
\hline k & - & 10 & düşme & 2 plak/ 5 vida/intraoral & simfiz \\
\hline e & - & 21 & darp & 3 plak/14 vida/intraoral & angulus/korpus \\
\hline e & - & 49 & darp & 4 plak/16 vida/intraoral & Çift taraflı angulus \\
\hline e & - & 26 & darp & 2 plak/ 8 vida/intraoral & angulus \\
\hline $\mathrm{k}$ & - & 51 & düşme & 2 plak/ 8 vida/intraoral & simfiz \\
\hline e & - & 60 & trafik $\mathrm{k}$. & 2 plak/ 8 vida/ekstraoral & kondil \\
\hline e & - & 31 & darp & 2 plak/ 8 vida/intraoral & simfiz \\
\hline e & - & 54 & trafik $\mathrm{k}$. & 4 plak/16 vida/intraoral & Simfiz ve karşı kondil \\
\hline e & - & 21 & darp & 2 plak/ 8 vida/intraoral & angulus \\
\hline e & - & 19 & trafik $\mathrm{k}$. & 4 plak/16 vida/intraoral & angulus ve simfiz \\
\hline k & - & 23 & darp & 2 plak/ 8 vida/intraoral & korpus \\
\hline e & imf vida & 58 & trafik $\mathrm{k}$. & 2 plak/ 10 vida/intraoral & Lefort 1 \\
\hline e & - & 46 & düşme & 1 plak/4 vida/intraoral & angulus \\
\hline k & - & 64 & trafik $\mathrm{k}$. & 2 plak/ 8 vida/intraoral & simfiz \\
\hline e & tel & 23 & darp & 2 plak/ 8 vida/ekstraoral & kondil \\
\hline e & - & 37 & darp & 1 plak/4 vida/intraoral & angulus \\
\hline e & - & 51 & düşme & 2 plak/ 8 vida/ekstraoral & kondil \\
\hline k & - & 43 & trafik $\mathrm{k}$. & 2 plak/ 8 vida/intraoral & simfiz \\
\hline e & - & 28 & darp & 3 plak/14 vida/intraoral & çift taraflı angulus \\
\hline e & imf vida & 34 & trafik $\mathrm{k}$. & 2 plak/ 10 vida/intraoral & Lefort 1 \\
\hline e & ark bar & 63 & trafik $\mathrm{k}$. & - & simfiz \\
\hline e & - & 17 & darp & 1 plak/6 vida/intraoral & angulus \\
\hline k & - & 44 & düşme & 1 plak/4 vida/intraoral & korpus \\
\hline e & ark bar & 67 & trafik $\mathrm{k}$. & - & simfiz \\
\hline e & - & 19 & darp & 2 plak/ 8 vida/ekstraoral & kondil \\
\hline e & - & 24 & darp & 2 plak/ 8 vida/intraoral & angulus \\
\hline e & - & 32 & darp & 2 plak/ 8 vida/intraoral & angulus \\
\hline e & ark bar & 44 & düşme & - & simfiz \\
\hline
\end{tabular}




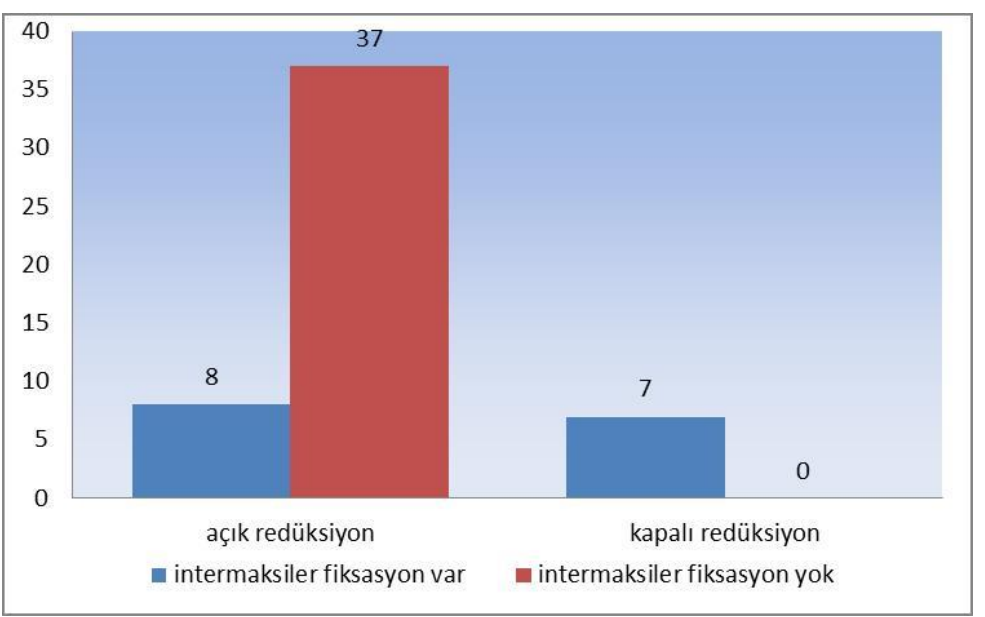

Şekil 3.

Kırıkların redüksiyon tiplerine göre dağılımı

\section{Intermaksiller fiksasyon yöntemi}

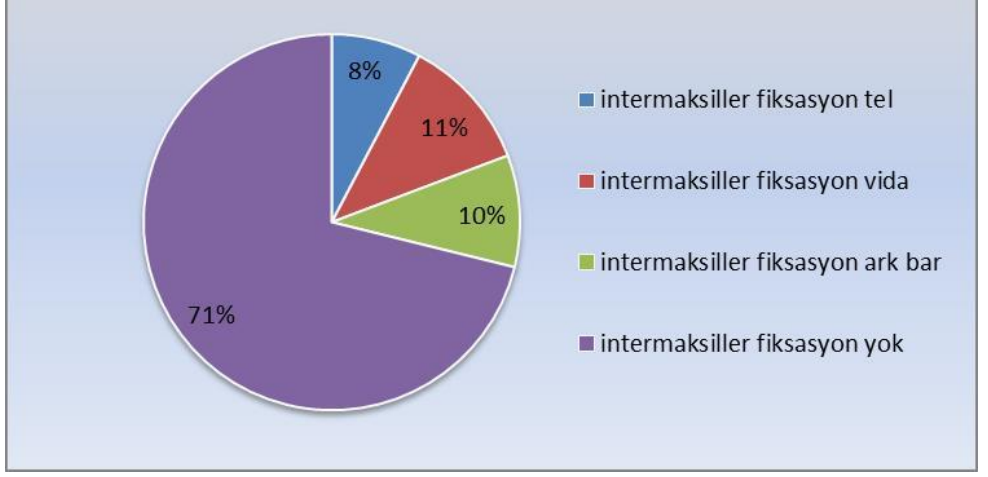

\section{TARTIŞMA}

Epidomiyolojik çalışmalarda elde edilen sonuçlar, değerlendirilmesi yapılan bireylerin ortak özelliklerine bağlı olarak değişiklikler göstermektedir. Çene yüz kırıklarının incelendiği çalışmalar göstermiştir ki; kırıkların etiyolojileri, görüldüğü yaş ortalaması, kadın erkek oranı, lokalizasyonları ve meydana geliş sebepleri toplumun kültürel yapısı, sosyoekonomik durumu, gelişim seviyesi gibi çeşitli faktörlerden etkilenmektedir. ${ }^{2,7-9}$ Çene yüz kırıkları; tüm vücut hasarları içerisinde \%45-60 oranında yüksek bir insidansa sahiptir. Teşhis ve tedavinin erken yapılması, çevre anatomik yapıların daha az zarar görmesi, diş ilişkilerinin doğru konumlanması, yüz ve çevresinde oluşacak estetik ve fonksiyonel sorunların ortaya çıkmamasını sağlayacaktır. ${ }^{1,4,6}$
Çene yüz kırıklarının cinsiyetler üzerine dağııımının değerlendirildiği çalışmalarda; erkek kadın oranı 2:1 ile 9.4:1 arasında değişen çeşitli oranlar göstermektedir.,5,8-12 Erkeklerde görülen bu yüksek oranın erkek toplumun sosyal ve fiziksel aktivitelerde daha baskın olarak yer alması bu sebeple de trafik kazaları, şiddet olayları gibi travmaya sebep verebilecek durumlarla daha sık karşılaşmalarına sebebiyet vermesinden kaynaklandığı düşünülmektedir. ${ }^{12}$ Çalışmamızda hastaların 40'ı erkek (\%77), 12'si kadın (\%23) ve erkek kadın oranı 3.3:1 olarak tespit edilmiştir, bu veriler dünya geneli verileri ile örtüşmektedir.

Literatürde çene yüz kırıklarının 20-30'lu yaş grubu arasında daha sık görüldüğü bildirilmiştir. 2,5,11,12 Bizim çalışmamızda da literatüre benzer şekilde kırık görülen hastaların yaş ortalaması 33.3 olarak tespit edilmiştir. Bu hastaların \%5.7'si 16 yaş altı, $\% 63.5^{\prime} i$ 16-40 yaş arası ve \%30.8'i ise 40 yaşından büyük olarak tespit edilmiştir. Boffano ve ark. ${ }^{5}$ yaptıkları Avrupa genelini kapsayan çok merkezli çalışmada; tüm merkezlerde kadınların yaş ortalamasının erkeklerden daha fazla olduğunu gözlemlemişlerdir. Ancak bizim çalışmamızda ortalama kadın yaşı 30,08 iken, ortalama erkek yaşı 34,28 olarak tespit edilmiştir. İki çalışma arasında gözlenen bu farkın çalışmamızın yapıldığı çevrenin sosyal değişkenlerinden kaynaklandığı düşünülebilir.

Güncel literatürler darp, trafik kazaları ve düşmenin çene yüz kırıklarının etiyolojisindeki en önemli faktörler olduğunu ve bu faktörlerin ülkenin sosyoekonomik, kültürel ve çevresel faktörlerinden de etkilendiğini göstermektedir. ${ }^{14,15}$ Hatta gelişmiş ülkelerde trafik kazalarına bağı görülen travma oranlarında azalma gözlenirken, gelişmekte olan ülkelerde trafik kazalarının hala ilk sırayı koruduğu bildirilmektedir. ${ }^{10,15,16}$ Bunun sebebi olarak da trafik kazaları önlemek amacıyla uygulanan yaptırımların denetiminin başarı ile sağlanmasına bağlamışlardır. ${ }^{5}$ Daha önce ülkemizde Erol ve ark. ${ }^{2}$ tarafından yapılan çalışmada ilk 3 sırayı trafik kazaları, düşme ve darp almıştır. Yine ülkemizde, Gönüllü ve ark. ${ }^{17}$ tarafından yapılan çalışmada düşme trafik kazası ve darp ilk üç sırayı almış ancak faktörler arasındaki dağılımın birbirine yakınlık gösterdiği tespit edilmiştir. Mevcut çalıșmamızda ise darp \%42 ile ilk sırada 
gözlenen etiyolojik faktör olarak tespit edilmiş ve bunu \%33 ile trafik kazaları ve \%25 ile düşme takip etmiştir. Oluşan bu fark çalışmanın yapıldığı çevrenin gelişmekte olduğunu, kişilerin şiddete eğilimli olduğunu düşündürebilir. Ayrıca trafik kazalarına maruz kalmış yaralıların ilk tedavi seçenekleri ilkyardım servisleri bulunmadığı için Diş hekimliği fakülteleri olmamaktadır. Trafik kazası ile çene yüz travmasına uğramış hastalardaki kııılar yakın ve uzak çevre illerde bulunan merkezlerin acil servislerinde tedavi edilmekte veya vücudundaki diğer hayati organların tedavisi ilk sıraya alarak çene yüz kıııkları gözardı edilebilmektedir.

Demir ve ark. ${ }^{19}$ tarafından yapılan çalışmada mandibuler kırıklar içinde en sık simfiz kırıklarının olduğu tespit edilmiştir. Yurtdışında gerçekleştirilen yüksek sayılı çalışmalarda mandibuler kırıklar içinde en sık gözlenen kırık lokalizasyonunun kondil kırığı olduğu tespit edilmiștir. ${ }^{5,15,20}$ 20 yaş dişinin varlığının mandibula kırıkları ile ilişkisine bakıldığı retrospektif çalıșmalarda ${ }^{21-23}$; yirmi yaş dişinin kondil kırığı insidansını etkilediği ve kırıma oranını azalttığı sonucuna varılmıştır. Çalışmamızda 52 hastada toplam 62 adet kırık tespit edilmiştir, gözlenen kıııların dağııımını incelediğimizde \%92'sinde mandibulada kırık tespit edilmiștir. Bu sonuç diğer çalışmaların sonuçları ile uyum içerisindedir. $9,11,16,18$ Mandibulada tespit edilen kırıkların kendi içerisinde oranları \%36,8 angulus, \% 33,3 simfiz, $\% 15,8$ kondil, \%8,8'si korpus $(n=5)$ ve $\% 5,3$ 'ü ramus $(n=3)$ olarak tespit edilmiștir. Kliniğimizde tedavisi yapılan kırıkların en çok angulus bölgesinde görülmesi; travmaların etiyoloji değişkenliği, 20 yaş dişlerinin ağızdaki konumu, ve hastaların angulus çevresindeki şikayetten diş hekimliği bölümünü tercih etmeleri olarak açıklanabilir.

Çene yüz kırıklarının incelendiği bir başka retrospektif çalışmada ${ }^{24}$ maksilla kııklarının, diğer kırıklara nazaran daha az oranda $(\% 11,2)$ görüldüğü belirtilmiştir. Çalışmamızda da maksilla kırıkları \%8 oranında olacak şekilde mandibulaya göre daha az tespit edilmiştir. Maksillada oluşan kırıklar daha yüksek enerjili kııılar olduğu ve çalışmamızın ana etiyolojik faktörünün de darp olduğu düşünüldüğü takdirde oranın düşük olması beklenilen bir durumdur.

Çene yüz kırıklarının tedavisi; kırı̆ın şiddeti, okluzyonun durumu, çevre anatomik yapıların durumu, teşhis ve cerrahi ekipman, hekimin bilgi, tecrübe ve tercihi gibi çeşitli faktörlere bağlı olarak değişkenlik gösterebilmektedir.

Çene yüz kırıklarının insidansı, etiyolojisi, hastaların demografik özellikleri bölgelere göre çeşitlilik göstermektedir. Bölgeler arasındaki farklılığın daha detaylı anlaşılabilmesi için coğrafik, sosyal ve ekonomik değişkenlere sahip sahaların katılacağı çok merkezli çalışmaların hem hastaların tedavisine hem de literatüre büyük katkı sağlayacağını düşünmekteyiz.

\section{Maddi destek ve çıkar ilişkisi}

Çalışmayı maddi olarak destekleyen kişi/kuruluş yoktur ve yazarların çıkara dayalı bir ilişkisi yoktur.

\section{Teşekkür}

$\mathrm{Bu}$ çalışmanın oluşmasını sağlayan verilerin sağlanması ve temininde büyük emeği olan Kırıkkale Üniversitesi Diş Hekimliği Fakültesi Ağız Diş Çene Cerrahisi Anabilim Dalı öğretim üyeleri Prof. Dr. Umut Tekin, Prof. Dr. Ercüment Önder, Doç. Dr. Doruk Koçyiğit ve Doç. Dr. Fethi Atıl'a teşekkür ederim. 


\section{KAYNAKLAR}

1. Ellis E, Moos KF, El-Attar A. Ten years mandibular fractures: An analysis of 2137 cases. Oral Surg Oral Med Oral pathol 1985; 59: 120-9.

2. Erol B, Tanrikulu R, Görgün B. Maxillofacial fractures. analysis of demographic distribution and treatment in 2901 patients (25-year experience). J CranioMaxillofacial Surg 2004; 32: 308-13.

3. Miloro M, Ghali G, Peterson L, Larsen P, Waite P. Peterson's Principles of Oral and Maxillofacial Surgery Volume 1,2nd Ed. Canada, BC Decker Inc, 2004.

4. Boffano $P$, Kommers SC, Karagozoglu $\mathrm{KH}$, Forouzanfar T. Aetiology of maxillofacial fractures: a review of published studies during the last 30 years. Br J Oral Maxillofac Surg 2014; 52: 901-06.

5. Boffano P, Roccia F, Zavattero E et al. European Maxillofacial Trauma (EURMAT) project: a multicenter and prospective study. J Craniomaxillofac Surg 2015; 43: 62-70.

6. Zhou HH, Liu Q, Yang RT, Li Z, Li ZB. Maxillofacial fractures in women and men: a 10 years retrospective study. J Oral Maxillofac Surg 2015; 73: 2181-8.

7. Laski R, Ziccardi VB, Broder H, Janal M. Facial trauma: a recurrent disease? The potential role of disease prevention. J Oral Maxillofac Surg 2004; 62: 685-8.

8. Lee K. Global trends in maxillofacial fractures. Craniomaxillofac Trauma Reconstruction 2012; 5: 21322.

9. Mijiti $A$, Ling $W$, Tuerdi $M$ et al. A.Epidemiological analysis of maxillofacial fractures treated at a university hospital, Xinjiang, China: a 5-year retrospective study. J Craniomaxillofac Surg 2014; 42: 227-33.

10.Gandhi S, Ranganathan LK, Solanki M, Mathew GC, Singh I, Bither S. Pattern of maxillofacial fractures at a tertiary hospital in northern India: a 4-year retrospective study of 718 patients. Dent Traumatol 2011; 27: 257-62.

11. Allareddy V, Allareddy V, Nalliah RP: Epidemiology of facial fracture injuries. J Oral Maxillofac Surg 2011; 69: 2613-8.

12. Kostakis G, Stathopoulos P, Dais $P$ et al. An epidemiologic analysis of 1,142 maxillofacial fractures and concomitant injuries. Oral Surg Oral Med Oral Pathol Oral Radiol 2012; 114: 69-73.

13.Kraft A, Abermann E, Stigler $R$ et al. Craniomaxillofacial trauma: synopsis of 14,654 cases with 35,129 injuries in 15 years. Craniomaxillofac Trauma Reconstr 2012; 5: 41-50.

14. Cabalag MS, Wasiak J, Andrew NE, Tang J, Kirby JC, Morgan DJ. Epidemiology and management of maxillofacial fractures in an Australian trauma centre. J Plast Reconstr Aesthet Surg 2014; 67: 183-9.
15. Chrcanovic BR, Abreu MH, Freire-Maia B, Souza LN. 1,454 mandibular fractures: a 3-year study in a hospital in Belo Horizonte, Brazil. J Craniomaxillofac Surg 2012; 40: 116-23.

16. Al-Khateeb T, Abdullah FM. Craniomaxillofacial Injuries in the United Arab Emirates: a retrospective study. J Oral Maxillofac Surg 2007; 65: 1094-101.

17.Gönüllü $H$, Karadaş $S$, Işık $D$, Koçak ÖF, Tekin $\mathrm{H}$. Bir Acil Servise Başvuran Maksillofasiyal Travma Olguları: Retrospektif Bir Çalışma Turk Plast Surg 2011; 19: 121-4.

18.Ansari MH: Maxillofacial fractures in Hamedan province, Iran: a retrospective study (19872001). J Craniomaxillofac Surg 2004; 32: 28-34.

19.Demir Z, Öktem F, Velidedeoğlu H, Çelebioğlu S. Maksillofasiyal Kırığı Olan 121 Olgunun Değerlendirilmesi Ve Literatürle Karşılaştırıması KBB-Forum 2008; 3: 85-90

20. lida S, Kogo M, Sugiura T, Mima T, Matsuya T. Retrospective analysis of 1502 patients with facial fractures. Int J Oral Maxillofac Surg 2001; 30: 286-90.

21.Deuk HM, Su GK, Seong YM, Ji So, Jae SY. Relationship betweeen mandibular condyle and angle fracturesand the presence of mandibular third molars. J Korean Assoc Oral Maxillofac Surg 2015; 41: 3-10.

22. Revanth Kumar S, Sinha R, Uppada UK, Ramakrishna Reddy BV, Paul D. Mandibular Third Molar Position Influencing the Condylar and Angular Fracture Patterns. J Maxillofac Oral Surg 2015; 14: 956-61.

23. Choi BJ, Park S, Lee DW, Ohe JY, Kwon YD. Effect of lower third molars on the incidence of mandibular angle and condylar fractures. J Craniofac Surg. 2011; 22: 1521-5.

24. Venugopal MG, Sinha R, Menon PS, Chattopadhyay PK, Roy Chowdhury SK. Fractures in the Maxillofacial Region: A Four Year Retrospective Study. Med J Armed Forces India. 2010; 66: 14-7.

\section{Yazışma Adresi:}

Dr. Öğr. Üyesi Özkan ÖzGÜL

Kırıkkale Üniversitesi

Diş Hekimliği Fakültesi

Ağız Diş ve Çene Cerrahisi AD

Yenişehir Mahallesi Çelebi Sokak No:1

Yahşihan, Kırıkkale

Tel : +90318224 4927 / 7134

E-mail: ozkanozgul@yahoo.com 